\title{
The "care" protocol: the role of personality in a three-year follow-up study of medication overuse headache
}

\author{
F Galli ${ }^{1}$, G Sances ${ }^{1 *}$, N Ghiotto ${ }^{1}$, A Frustaci ${ }^{2}$, E Guaschino ${ }^{1}$, G Nappi ${ }^{1}$, C Tassorelli ${ }^{1}$ \\ From The European Headache and Migraine Trust International Congress \\ London, UK. 20-23 September 2012
}

\section{Introduction}

The negative prognostic value of psychiatric disorders in Medication Overuse Headache [1] has been previously outlined, however, to the best of our knowledge, the role of personality factors as potential predictors of $\mathrm{MOH}$ evolution has never been studied. Aim of this study was to analyse the role of personality in the prognosis of $\mathrm{MOH}$.

\section{Methods}

Among a total of 243 patients, 150 completed the followup at three years $(79.3 \%$ females, age $46.40 \pm 11.31)$. The personality profile was assessed with the Minnesota Multiphasic Personality Inventory (MMPI-2). We explored the occurrence (or not) of at least one episode of drug overuse taking into account the overall 3-year period of follow-up. Our population was subdivided into 3 groups: Group A (patients who never stopped overusing drugs after the initial detoxification treatment $(\mathrm{N}=13)$ ); Group B (patients who stopped drug overuse following detoxification, but then relapsed at least once $(\mathrm{N}=38)$ ); Group $\mathrm{C}$ (stopped drug overuse following detoxification and never relapsed $(\mathrm{N}=99))$.

\section{Results}

As regards personality profile at MMPI-2, subjects in Group A had higher scores at the Lie scale $(\mathrm{p}=0.004)$ as compared to both the other groups ( $\mathrm{B}$ and $\mathrm{C}$ ), and at the following scales as compared to patients who stopped abuse and never relapsed (Group C): Frequency $(\mathrm{p}=0.020)$, Hypocondriasis $(\mathrm{p}=0.007)$, Depression $(\mathrm{p}=0.003)$, Paranoia $(\mathrm{p}=0.025)$, Fears $(\mathrm{p}=0.003)$, Obsessiveness $(\mathrm{p}=0.026)$,
Bizarre Mentation ( $\mathrm{p}=0.046)$, Social Discomfort $(\mathrm{p}=0.004)$, Negative Treatment Indicators $(\mathrm{p}=0.040)$, Repression $(\mathrm{p}=0.007)$, Overcontrolled Hostility $(\mathrm{p}=0.040)$, Addiction Admission Scale $(\mathrm{p}=0.021)$, Social Responsibility $(\mathrm{p}=0.039)$ and Marital Distress $(\mathrm{p}=0.028)$.

\section{Conclusions}

Personality is important not only because they characterise patients with $\mathrm{MOH}$, but also probably for their outcome predicting value. We provide support for the existence of a small sub-group of $\mathrm{MOH}$ patients (Group A) with addiction-related personality and behavioural problems that are likely to play a major role in influencing and nurturing drug abuse and chronic headache.

\section{Author details}

${ }^{1}$ Headache Science Centre of the IRCCS 'National Institute of Neurology C. Mondino' Foundation, Pavia, Italy, Italy. ${ }^{2}$ Clinical and Molecular Epidemiology, IRCCS San Raffaele Pisana, Rome, Italy, Italy.

Published: 21 February 2013

\section{Reference}

1. Hagen $K$, Linde M, Steiner TJ, Stovner LJ, Zwart JA: Risk factors for medication-overuse headache: An 11-year follow-up study. The NordTrondelag Health Studies. Pain 2011, 153(1):56-61.

\section{doi:10.1186/1129-2377-14-S1-P174}

Cite this article as: Galli et al:: The "care" protocol: the role of personality in a three-year follow-up study of medication overuse headache. The Journal of Headache and Pain 2013 14(Suppl 1):P174. 